\title{
Detecting the Evolution of Collective Memory Space Using a Space Syntax-Based Analysis Method in Beiyuanmen Historical and Cultural Block
}

\author{
Siqi Gao', Lu Han'1, Chunhui Li' ${ }^{1}$ Lizhi Zhao² \\ ${ }^{1}$ Architectural Design \& Research Institute of Tsinghua University, Co., Ltd., Beijing, China \\ ${ }^{2}$ China University of Mining \& Technology (Beijing), Beijing, China \\ Email: siqigao@foxmail.com
}

How to cite this paper: Gao, S. Q., Han, L., Li, C. H., \& Zhao, L. Z. (2021). Detecting the Evolution of Collective Memory Space Using a Space Syntax-Based Analysis Method in Beiyuanmen Historical and Cultural Block. Current Urban Studies, 9, 744-758. https://doi.org/10.4236/cus.2021.94044

Received: November 13, 2021

Accepted: December 7, 2021

Published: December 10, 2021

Copyright ( 2021 by author(s) and Scientific Research Publishing Inc. This work is licensed under the Creative Commons Attribution International License (CC BY 4.0).

http://creativecommons.org/licenses/by/4.0/

\section{(c) (i) Open Access}

\begin{abstract}
With the rapid development of globalization and urbanization, the atmosphere of cultural life in the historical and cultural districts of the city has begun to change. The collective memory of the block is gradually missing, and the local crisis of homogenization appears. Therefore, the Beiyuanmen block was selected as a typical case, using spatial syntax and in-depth interviews to empirically study the collective memory of residents. It is found that the collective memory space of Beiyuanmen block has the following changing trends: the collective memory space structure level of the block continues as a whole, and the alley space that carries the residents' unconscious habitual memory is facing varying degrees of destruction; the scope and intensity of collective memory space are consistent with the direction of urban development, and the overall collective memory center tends to shift westward; the elements of collective memory space have changed obviously, from being dominated by a single religious building function in the old period to a coexistence pattern of religious buildings and public facilities in the new period. Based on the above analysis, it is considered that the collective memory space in historical and cultural blocks is the result of the transformation of residents' values and ethnic interaction.
\end{abstract}

\section{Keywords}

Collective Memory, Space Syntax, Beiyuanmen Block, Space Evolution

\section{Introduction}

Historical and cultural blocks inherit the natural growth mechanism of cities, 
keep rich memories of cities, and play an important role in protecting historical features and highlighting local characteristics. In recent years, under the influence of large-scale construction activities, population structure adjustment, and changes in modern life needs, the phenomenon of urban homogeneity in appearance has generally appeared. Low rental cost and proximity to downtown districts of historical and cultural blocks attract the flooding in of migrants. Historical and cultural blocks began to suffer from memory loss and emotional fracture due to the influence of the gathering of immigrants on the locality and authenticity of the blocks (Wang et al., 2017). Therefore, it has become the important content to retain the "gene" of urban characteristics to tap the rich memory elements of urban historical and cultural blocks and reshape the sense of identity and belonging of residents in the blocks.

Collective memory was put forward by French social psychologist Maurice Halbwachs, who defined it as the process and result of sharing the past by members of a specific social group. In other words, collective memory is attached to the material reality and shared by the group (Maurice, 2002). Aldo Rossi considers that cities are places of collective life and memory, and begins to emphasize the historical value of the relationship between collective and place (Kuijk et al., 2010). Collective memory, as a hidden dynamic system, is the common memory generated by social groups in a specific place in various time sections, which is usually attached to various material or non-material carriers for visualization, preservation and transmission. Collective memory needs to be expressed and recognized in the way of spatial existence. It means that space is the container carrying collective memory, and collective memory is the connotation information accumulated in space. They are inseparable. At the same time, besides the memory carrier, the collective memory cannot be separated from the subjective consciousness and emotion of human, which reflects the relationship between time, space and social groups in the urban geography category.

With the in-depth study of collective memory, Nagel took Beirut, the capital of Lebanon, as an example to study the selection and construction of national collective memory in the post-war reconstruction process (Nagel, 2002). David took the Dock Village in Victoria, England as an example to study the spatial production of collective memory in daily living areas (David, 2007). Mah studied Newcastle's declining shipbuilding industry landscape and the memories of local residents (Mah, 2010). Ardakani pointed out that collective memory is an important driving force for the sustainable protection of historical cities. Collective memory is evoked, which can trigger local identity and strengthen local attachment. If it is ignored or forgotten, the historical area is likely to lose its social and cultural capabilities (Ardakani \& Oloonabadi, 2011). Alderman studied the street renaming phenomenon in the southern United States in order to commemorate Martin Luther King, evoke historical memory, and establish the status of black society (Alderman \& Inwood, 2013). In terms of research methods, Steven used early topographic maps, old photos, and local history to help residents confirm facts and recall memories (Steven \& Alderman, 2004). Daniel used portable re- 
cording and information interaction technology to record the sensory and psychological responses of participants' brains and bodies into the environmental landscape anytime and anywhere to reflect the memories evoked by the landscape (Daniel, 2004). Maria used a large-scale questionnaire to investigate the collective memory, identity and attachment of residents about the place after the border changes (Maria, 2008). Zhou Wei selected the Nanjing Confucius Temple block as a typical case, using cognitive maps, oral interviews and GIS spatial statistics methods to empirically study the collective memory of residents in urban streets and alleys (Zhou \& Huang, 2016). Li Zhifei used grounded theory from the perspective of tourists to study the role of collective memory in the local attachment of tourists in cultural tourism destinations and analyzed the internal reasons (Li \& Nie, 2018).

In summary, the research objects of collective memory have shifted from political spaces, national landscapes, and memorial landscapes to secular spaces such as daily life, rural landscapes, and abandoned landscapes. Cases have also gradually expanded from traditional museums and memorial landscapes to cultural heritage and industrial heritage, focusing on topics such as historical space protection, site reconstruction, and urban renewal. The research method is based on field surveys in geography, and fully borrows from other humanities and social sciences. It focuses on case studies, rich in case studies, and qualitative research. There are few quantitative studies and model constructions.

At present, the research on the interaction between collective memory and space mostly adopts cognitive methods based on subjective evaluation, such as a cognitive map method and scene identification method, which are greatly influenced by the subjective education background, cognitive ability and expression ability of cognitive subjects. However, space syntax can link the non-material information "memory" based on the time dimension with the material attributes of the "place" based on the space dimension and express it structured through graphic language, because its characteristic of recognizing the object through the subject's behavior. Therefore, this research proposes to use space syntax, supplemented by interviews, to establish a relationship chain combining three dimensions of subject cognition, object response, and time process. The proposed method is explored through a case study of Beiyuanmen block, in which the characteristics and evolution trend of collective memory space including spatial structure, shape center, element attributes is analyzed. And the internal mechanism of the change of collective memory behind the process of block change is also discussed, in order to provide help for the theoretical research on the excavation, protection and inheritance of collective memory of historical and cultural blocks in China.

\section{Study Area and Methods}

\subsection{Study Area}

Beiyuanmen block, also known as Huifang, is located in the core area of the old 
city of Xi'an. It is the most well-preserved and largest traditional residential historical and cultural block in the old city of Xi'an, and is also one of the most representative Hui inhabited areas in mainland China (Yang et al., 2004). The reasons why Beiyuanmen block is chosen as the research object are as follows. On the one hand, the region has the traditional foundation of historical and cultural block, and the formation of its collective memory space is relatively mature from the time dimension. On the other hand, due to the obvious impact of globalization and urbanization, its population composition is more complex. The main types of local people are local residents, service workers in the tertiary industry and foreign tourists. The changes of Beiyuanmen block in terms of society, economy and space are all representative, and the temporal and spatial evolution of collective memory space is also more typical.

The reasons for selecting the representative "time period" which influenced the evolution of collective memory space in historical and cultural blocks are as follows (Huang, 2010). The collective memory space in Beiyuanmen block before 1911 was mainly influenced by feudal politics, economy and culture. Before 1911, the collective memory space of Beiyuanmen block evolved in a natural and organic way under the background of feudal rule. Therefore, the district preserved relatively complete spatial structure and morphological mechanism. During the Republic of China, Xi'an formulated several rounds of urban planning, but they were seldom implemented. The urban construction changed little. The spatial structure of the district changed drastically with the gradual implementation of the first round comprehensive planning in Xi'an until the founding of the People's Republic of China. After 1978, under the background of rapid economic development and urban expansion, the protection of historical and cultural blocks has received more and more attention, and a series of protection and renewal measures have been implemented. In view of this, and limited by the data, this research will divide into three periods to analyze the temporal and spatial evolution of collective memory space in Beiyuanmen block, which are feudal tradition period (before 1911), economic recovery period (1911-1975) and rapid development pe$\operatorname{riod}(1975-2020)$.

\subsection{Methods}

The proposed space syntax-based analysis method contains three main parts. The first part is to collect historical maps and satellite remote sensing maps of various typical years in Xi'an's development process. In order to further reveal the collective memory space characteristics of historical and cultural blocks, this paper puts historical and cultural blocks in a larger urban area for embedded system analysis, and draws the street texture of Xi'an in 1911, 1975 and 2020 respectively (Shi, 1996). The convergence effect of high road movement and accessibility on people flow information attracts the convergence of elements in collective memory space. The collective memory space itself enhances the convergence ability of roads due to its outstanding attributes and activities. There is a 
high coupling between them. Therefore, Depth map software is selected to analyze the choice and integration of blocks, combined with the spatial function and other factors, to express the degree of collective memory of the space. In the second part, since the collective memory research of the local elderly group is more representative, this paper selects 40 local elderly people in Beiyuanmen block for indepth interviews after field investigation and data access. Streets, parks, squares, schools and fairs around residents usually retain rich and diverse collective memories, neighborhood emotions and traditional spirits, which are the places where ordinary citizens rely for their lives, work, leisure, social exchanges and cultural identity. Thus, the interview content mainly includes the layout cognition, evolution and historical events of street space, public buildings and landscape in the block, which basically covers various forms of collective memory in Beiyuanmen block. Thirdly, according to the collective memory space mentioned by residents, combined with historical documents, the distribution of points is determined through Baidu maps and historical maps. Overlapping with the space syntax analysis diagram, so as to explore the evolution characteristics and internal mechanism of collective memory space.

\section{Analysis of Collective Memory Space}

\subsection{Evolutionary Characteristics of Collective Memory Spatial Structure}

The meaning of choice values is that the shortest path between any other two line segments within a certain radius of a certain line segment can be obtained (Guo \& Quan, 2013). A space with a higher degree of choice indicates a place that residents pass more frequent. And it mainly carries the mediocre and repetitive daily activities of residents. This daily content is not only the source of authenticity and locality of historical and cultural blocks, but also an important part of collective memory. Based on the consideration of the actual spatial scale, the analysis of the angular segment choice of the Beiyuanmen block is carried out (Figure 1). As it was shown, the standard deviation of choice in each period gradually decreases. It indicates that the street space, especially the alley space, still has higher frequency of use. When the topological radius is less than $500 \mathrm{~m}$, the residents in the block mainly travel by casual walking, generally through the alley space. When the topological radius reaches $2000 \mathrm{~m}$, residents travel mainly by purposeful vehicles, generally through street space. The Beiyuanmen block still continues the traditional "long streets and short alleys" spatial structure, which has a high degree of integration with the collective memory represented by the residents' lives. However, it should be noted that the number of streets and alleys has shown a significant reduction trend, from 103 in 1975 to 80 in 2020 , and the collective memory of daily activities it carries is also threatened.

In the traditional feudal period, when the residents travel distance is 500 meters, the areas with the highest choice of streets and alleys, that is, the areas where residents walk most frequently are the intersection of West Street and 


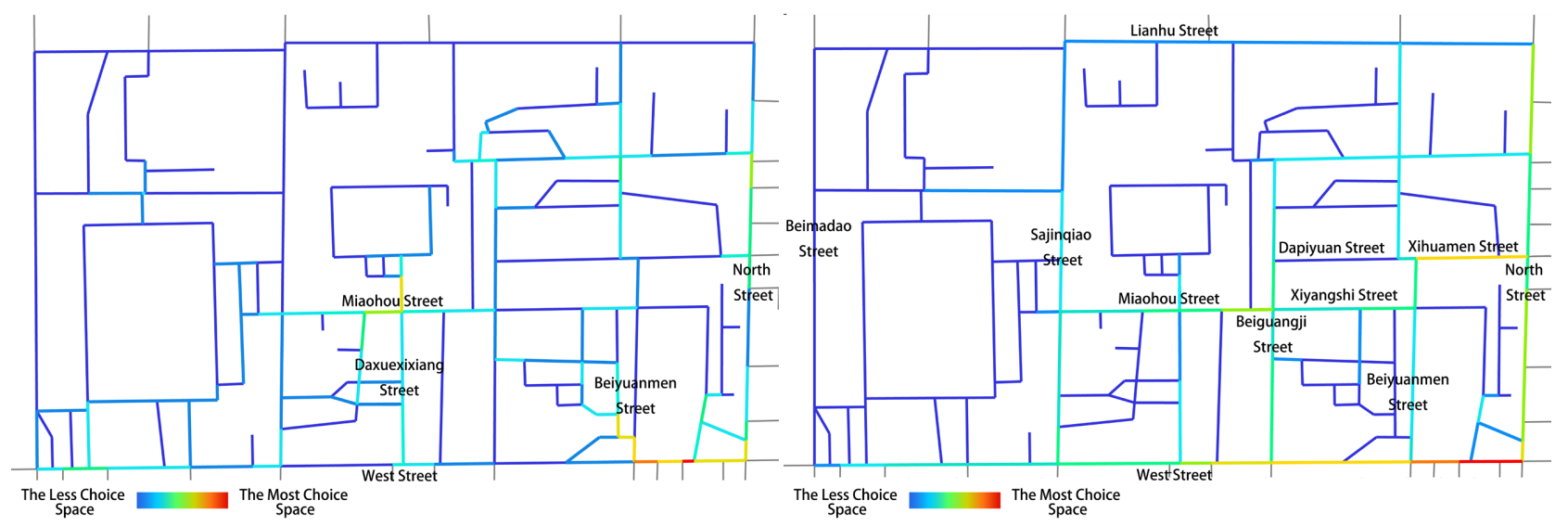

(a)

(b)

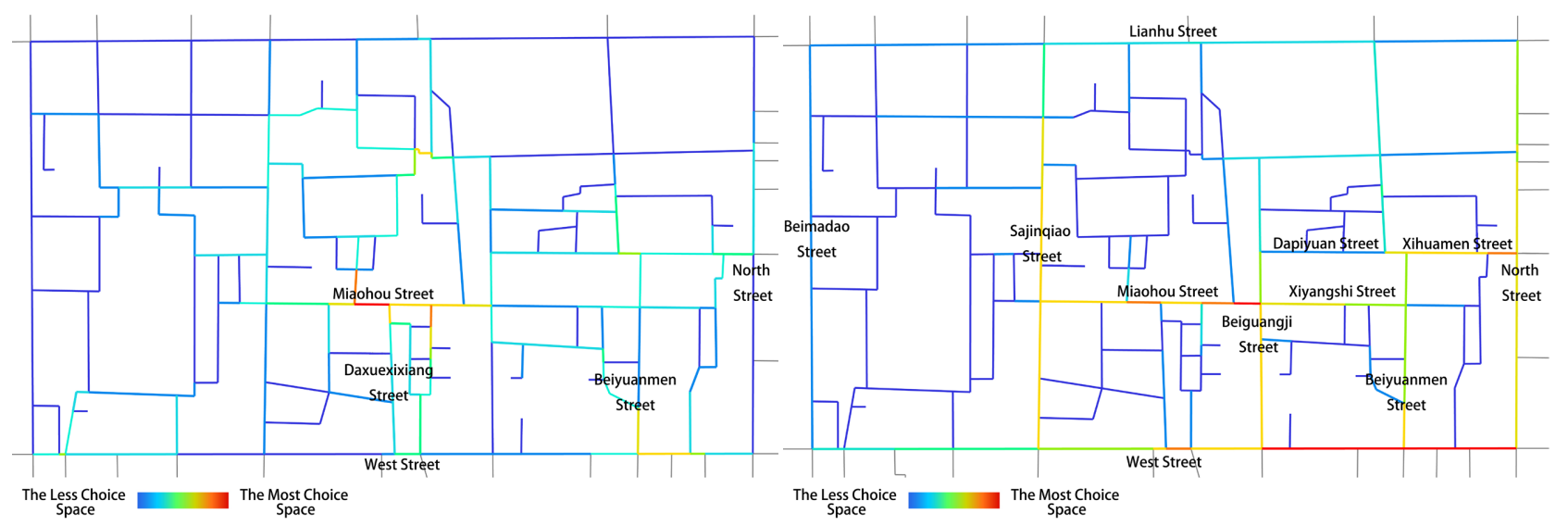

(c)

(d)

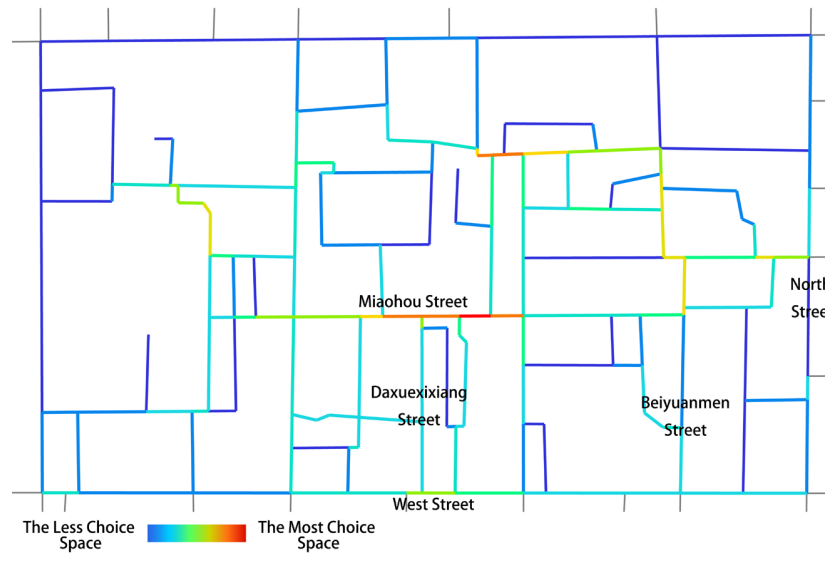

(e)

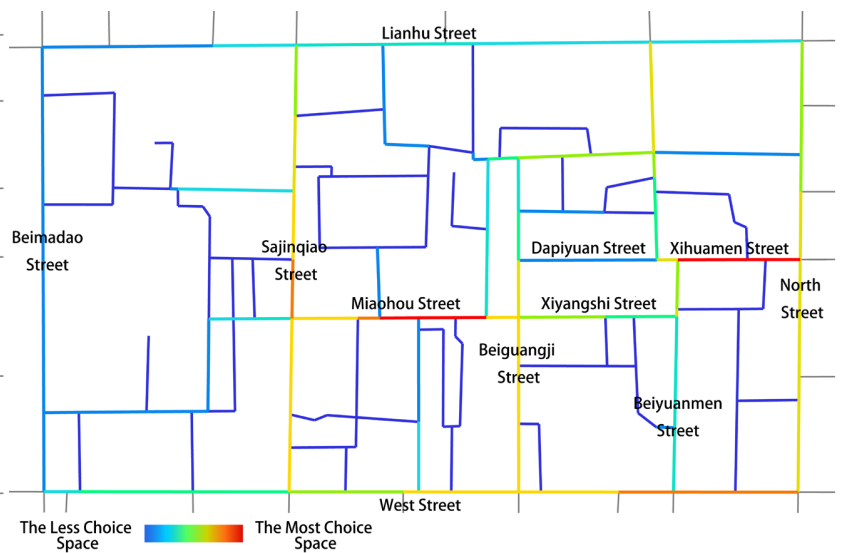

(f)

Figure 1. Transformation in choice maps of years 1911, 1975 and 2020. (a) Angular segment choice radius 500 in year 1911 map; (b) Angular segment choice radius 2000 in year 1911 map; (c) Angular segment choice radius 500 in year 1975 map; (d) Angular segment choice radius 2000 in year 1975 map; (e) Angular segment choice radius 500 in year 2020 map; (f) Angular segment choice radius 2000 in year 2020 map. Source: authors.

Beiyuanmen Street, and the intersection of Miaohou Street and Daxuexixiang Street. As a bridge between the internal space of the block and the external urban 
space, Beiyuanmen Street plays an important role in promoting the integration of internal social activities and external service functions of the block. When the travel distance reaches 2000 meters, residents mainly travel through West Street, forming a relatively independent pedestrian and vehicle branch system from Miaohou Street. However, the importance of the intersection of West Street and Beiyuanmen Street in residents' walking choices has gradually decreased. The importance of Miaohou Street has gradually increased, occupying a higher position in the spatial perception and collective memory of residents. At the same time, residents' car travel is no longer concentrated on West Street. Miaohou Street has also become the main channel of choice for car dealers. Miaohou Street has long been an area for residents to walk through daily, and it has become a place for residents to communicate with neighbors and fulfill their daily needs. The spatial scale of the street and functions of the buildings on both sides can also prove that Miaohou Street is a pedestrian service-oriented street. The current situation of mixed pedestrians and vehicles will inevitably cause inconvenience to the daily activities of the residents in the neighborhood. It also has a negative impact on the collective memory formed in daily activities.

\subsection{Evolutionary Characteristics of Collective Memory Spatial Morphology Center}

In space syntax analysis, local integration value at walking scale is usually used to analyze the accessibility of the space and the possibility of being selected as a travel destination. The higher the space accessibility, the easier it is for people to gather. This means that the collective memory of the space is higher. Figure 2 depicts a shift of intensified distribution from 1911 to 2020 and a decrease in local integration values from 1.87 to 2.30 . Affected by the Xi'an city center, the local integration degree of the block in different periods are of characteristics of south-high and north-low, the east-high and west-low. The axes with the highest degree of local integration is concentrated in Beiyuanmen Street-Beiguangji StreetMiaohou Street-Sajinqiao Street, forming the core area of collective memory in Beiyuanmen block. The overall integration capability of the eastern integrated core (the section of Beiyuanmen Street and Beiguangji Street) is significantly higher than that of the western integratied core (the section of Sajinqiao Street and Miaohou Street). Among them, the residents in the eastern integrated core have the most active social activities, and it is also the area with the highest degree of collective memory among historical and cultural blocks.

In the feudal tradition period, there was little difference in the local integration value of the streets in the core area of integration. With the implementation of the first round of overall planning in Xi'an, Sajinqiao Street has become the only main axis that crosses the whole block and runs through the north and south of Xi'an city. As a result, the local integration value of Sajinqiao Street has been significantly improved. In 1993, Beiyuanmen Street was built into a cultural tourism street with architectural style in Ming and Qing Dynasties (Xi'an Local Records Office, 2010). 


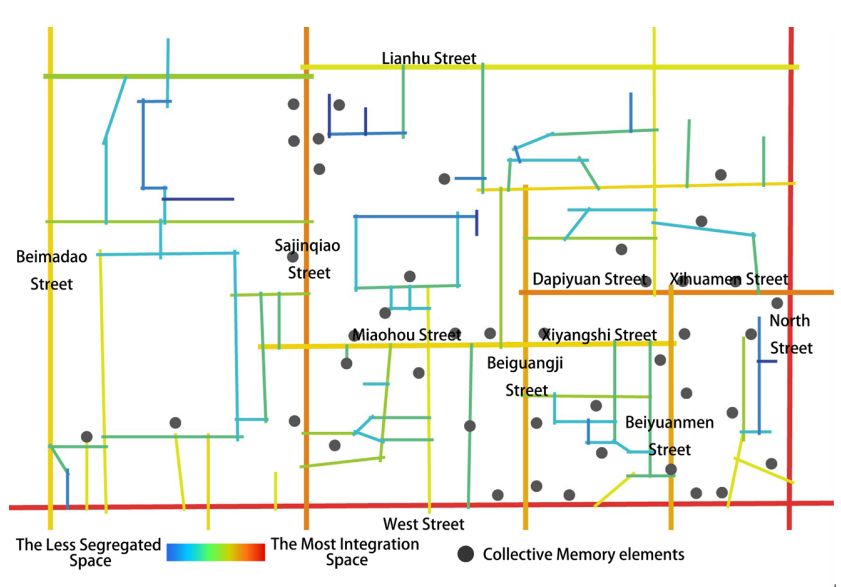

(a)

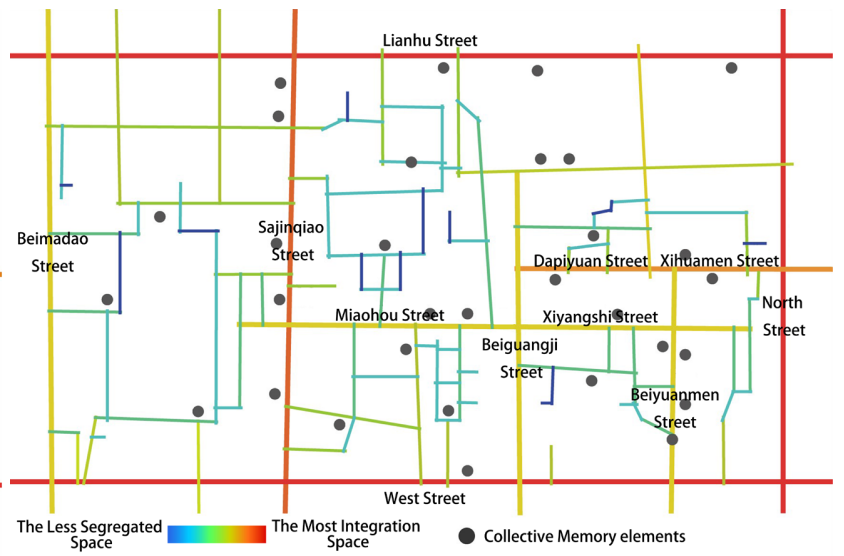

(b)

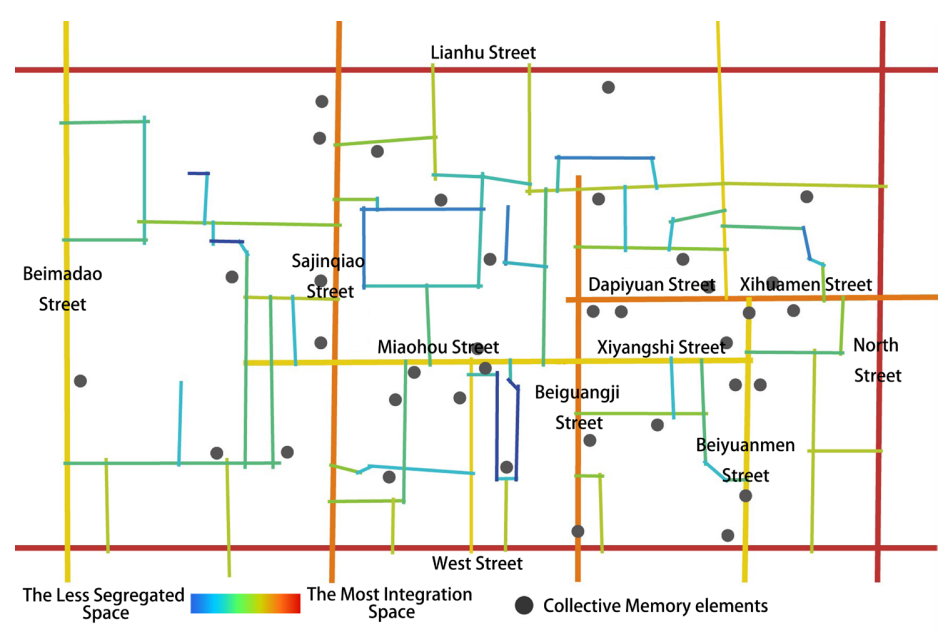

(c)

Figure 2. Transformation in local integration maps of years 1911, 1975 and 2020. (a) Local integration in year 1911 map; (b) Local integration in year 1975 map; (c) Local integration in year 2020 map. Source: authors.

The consumption demand of tourists has catalyzed the development of those industries dominated by tourism services. According to the survey, catering industry accounted for $69.3 \%$ of the total business volume in Beiyuanmen Street. The life service functions serving the residents in the block began to move to Beiguangji Street and Miaohou Street. Therefore, the local integration degree of Beiguangji Street has been greatly improved, and its axis status has risen from No. 4 to No. 2. Beiyuanmen Street and Xihuamen Street, as street axes mainly serving tourists, have dropped in status, under the interference of tourism development, the spatial form center of residents' collective memory has a westward shift trend (Table 1).

\subsection{Evolutionary Characteristics of Collective Memory Spatial Feature Attributes}

Based on residents' interviews and historical data, this article identifies 48, 31, and 36 collective memory space elements in the feudal tradition period, the eco- 
nomic recovery period, and the preservation and renewal period. There are only 15 spatial elements in the collective memory of residents in each period, which means that more elements are replaced in the evolution of collective memory space. In this paper, the spatial elements of collective memory in each period are divided into five types according to different functions, including administrative office, production and life, religious activities, entertainment and leisure, and historical heritage. As shown in Table 2, the essential attributes of feudal tradition period are mainly religious activities and administrative offices. After entering the period of economic recovery, the number of administrative office elements and religious activities elements has been greatly reduced. It intuitively reflects the historical background that the old system was overthrown and the new society, politics, economy, and culture were restructured. During the period of rapid development, the spatial elements of administrative office headed by Xi'an Municipal Government were successively moved away due to the influence of the land value of the central city. With the improvement of residents' living needs and the diversified development of values, the types of public buildings in the block are becoming more and more abundant. The proportion of production and living elements is greatly increased. At the same time, the number of mosques has increased significantly due to factors such as population growth and sect division. The block is still dominated by the collective memory elements of religious activities.

Table 1. Axes status change of local integration degree in Beiyuanmen block.

\begin{tabular}{|c|c|c|c|c|c|c|c|}
\hline \multirow{3}{*}{ Morphological center } & \multirow{3}{*}{ Street name } & \multicolumn{2}{|l|}{ In 1911} & \multicolumn{2}{|l|}{ In 1975} & \multicolumn{2}{|l|}{ In 2020} \\
\hline & & Local & Axes & Local & Axes & Local & Axes \\
\hline & & integration value & status & integration value & status & integration value & status \\
\hline \multirow{3}{*}{$\begin{array}{l}\text { The section of Beiyuanmen } \\
\text { Street and Beiguangji Street }\end{array}$} & Beiyuanmen Street & 3.29 & 3 & 3.46 & 3 & 3.37 & 4 \\
\hline & Xihuamen Street & 3.30 & 2 & 3.92 & 2 & 3.78 & 3 \\
\hline & Beiguangji Street & 3.27 & 4 & 3.43 & 4 & 3.99 & 2 \\
\hline \multirow{2}{*}{$\begin{array}{l}\text { The section of Sajinqiao } \\
\text { Street and Miaohou Street }\end{array}$} & Miaohou Street & 2.98 & 5 & 3.27 & 5 & 3.33 & 5 \\
\hline & Sajinqiao Street & 3.42 & 1 & 4.06 & 1 & 4.13 & 1 \\
\hline
\end{tabular}

Table 2. Changes of collective memory spatial function in Beiyuanmen block.

\begin{tabular}{|c|c|c|c|c|}
\hline Spatial function & $\begin{array}{c}\text { Feudal tradition } \\
\text { period (frequency) }\end{array}$ & $\begin{array}{l}\text { Economic recovery } \\
\text { period (frequency) }\end{array}$ & $\begin{array}{l}\text { Rapid development } \\
\text { period (frequency) }\end{array}$ & Memory intensity \\
\hline Administrative office & $39.58 \%(19)$ & $17.86 \%(5)$ & $2.78 \%(1)$ & reduce \\
\hline Production and living & $14.58 \%(7)$ & $35.71 \%(10)$ & $38.89 \%(14)$ & heighten \\
\hline Religious activities & $35.42 \%(17)$ & $32.14 \%(9)$ & $41.67 \%(15)$ & First decrease and then increase \\
\hline Entertainment and leisure & $0 \%(0)$ & $7.14 \%(2)$ & $11.11 \%(4)$ & heighten \\
\hline Historical heritage & $10.42 \%(5)$ & $7.14 \%(2)$ & $5.56 \%(2)$ & reduce \\
\hline
\end{tabular}


In addition, there are great differences in the situation of collective memory space elements existing in different periods in the process of block evolution. As shown in Table 3, the completely preserved space elements in Beiyuanmen block are all mosques. And the local integration value of each mosque is higher than the average value of the block of 2.30. This shows that the mosque always occupies an important central position in the social life of the block, and reveals that the collective memory of the Beiyuanmen block has typical local roots and religious dependence. Those spatial elements that have changed the original functions or buildings, because they are located in the core area of the block or assume important use functions, still maintain a high degree of collective memory (local integration is as high as 3 or more). However, during the interview, it was found that the historical significance and cultural connotation carried by this type of space element showed signs of diminishing in the hearts of residents. Those who have been completely demolished, leaving only the hidden spatial elements of place names, such as Fubiao teaching center, have lost their functional effect, and the local integration degree is only 1.82 , resulting in poor accessibility and declining status in the hearts of residents There is also a type of spatial elements that are rebuilt in other places after the destruction of modern construction. Mingyuanlou, the representative building of Shanxi Gongyuan, was moved to Revolution Park and renamed Revolution Pavilion during the economic recovery

Table 3. Evolution form of spatial elements of collective memory in Beiyuanmen block.

\begin{tabular}{|c|c|c|c|}
\hline $\begin{array}{l}\text { Evolution types of } \\
\text { collective memory }\end{array}$ & $\begin{array}{l}\text { Evolution model of collective } \\
\text { memory }\end{array}$ & Element name & $\begin{array}{l}\text { Local Integration } \\
\text { value }(2020)\end{array}$ \\
\hline \multirow{7}{*}{$\begin{array}{l}\text { Stable inheritance } \\
\text { of space }\end{array}$} & \multirow[t]{7}{*}{ Original site and building } & Huajuexiang Mosque & 2.69 \\
\hline & & Daxuexixiang Mosque & 3.20 \\
\hline & & Dapiyuan Mosque & 3.78 \\
\hline & & Xiaopiyuan Mosque & 2.85 \\
\hline & & Xiaoxuexixiang Yingli Mosque & 2.79 \\
\hline & & Beiguangji Mosque & 3.99 \\
\hline & & Sajinqiao Mosque & 4.13 \\
\hline \multirow{5}{*}{$\begin{array}{l}\text { Functional "compromise" } \\
\text { Inheritance }\end{array}$} & \multirow{5}{*}{$\begin{array}{l}\text { Original site, original function, } \\
\text { new building, or original site, } \\
\text { new function, original building }\end{array}$} & The Drum Tower & 3.37 \\
\hline & & Gaojia Courtyard & 3.23 \\
\hline & & Chenghuang Temble & 4.59 \\
\hline & & Xi' an No. 25 high school & 3.23 \\
\hline & & Lianhu district government & 3.78 \\
\hline \multirow{2}{*}{$\begin{array}{l}\text { Inheritance of recessive } \\
\text { spatial elements }\end{array}$} & \multirow{2}{*}{$\begin{array}{l}\text { Original site, new function, } \\
\text { new building, original name }\end{array}$} & Xicang & 2.10 \\
\hline & & Jiaochangmen (Fubiao Jiaochang) & 1.82 \\
\hline $\begin{array}{l}\text { Reconstruction and inheritance } \\
\text { in other places }\end{array}$ & $\begin{array}{l}\text { New address, new function, } \\
\text { original building (imitation) }\end{array}$ & $\begin{array}{l}\text { Revolutionary Pavilion (Mingyuanlou, } \\
\text { Shanxi Gongyuan) }\end{array}$ & 1.26 \\
\hline
\end{tabular}


period, which has almost been forgotten by local residents.

\section{Mechanism of Evolution of Collective Memory Space}

The evolution of collective memory in Beiyuanmen block is affected by the external intervention of urban transformation and the self-motivation of its own evolutionary organizational process. The intervention of urban transformation, such as the lifestyle change of social progress, urban construction under the background of market economy and the planning orientation of urban public policies, will inevitably drive the development of historical blocks with regional advantages. Only when the historical block retains its essential characteristics in the process of its own evolutionary organization, the typicality of this place different from other historical and cultural blocks can be achieved. Otherwise, it will lead to disintegration or even extinction. Therefore, the self-motivation mechanism behind the evolution of collective memory in the block is mainly analyzed.

\subsection{Changes in Values}

As a complete ethnic community, Beiyuanmen block is actually a more diversified combination of church blocks under its overall structure. Religious culture transcends the category of blood kinship and has a powerful binding and cohesive effect on residents. Mosques are not only religious centers, but also cultural centers and educational centers. It plays a strong role in identity construction for residents. The residential pattern of "living around the temple" was formed and continues to this day. Social progress has brought about changes in people's way of life, and residents' values have also altered. First, the individual self-awareness has been significantly enhanced. For the pursuit of interests, residents' behaviors that destroy the spatial structure of block collective memory, such as self-construction, road occupation along the street and re division of traditional courtyards, are becoming more rampant in the Beiyuanmen historical and cultural block Secondly, social values are showing a diversified development trend. The growth of mosques in the Beiyuanmen block was due to the division of sects caused by the differentiation of value orientations. Thirdly, the culture is showing a tendency of secularization. The rapid development of the private economy and the overall commercialization of the block have gradually separated religious life from secular life. Some residents even worship at home because of busy business, the sense of occasion toward the religious activity has declined. The proportion of Hui Minority people who go to mosques for daily religious activities also shows a trend of declining with age. At the same time, public service facilities have become more diversified under the promotion of the cultural inclusiveness of the younger generation, and combined with the mosque to form a complex center of the block.

The above-mentioned changes in values are the inevitable outcome of pursuing the maximization of benefits in social development. In the collision and 
communication with modern civilization, it not only changed some characteristics of collective memory space, but also promoted the sense of local identity within the ethnic group. National characteristics have always been the essential feature that distinguishes the Beiyuanmen block from other historical and cultural blocks in the city. Although the spatial control effect of mosques in the block has decreased significantly, the strong centripetal force and sense of identity caused by the mosques still effectively organize residents together. For example, the reconstruction of Dongjuyuan alley in 1994 and Sajinqiao Street in 2004 both negotiated with government departments under the joint organization of mosques (Han \& Wang, 2018). The interests of residents and the collective memory of the block are protected.

\subsection{Interaction between Ethnic Groups}

After 1978, the strong development of tourism in Beiyuanmen block caused a sharp increase in labor demand. A large number of foreign operators and tourist immigrant workers flooded into the block. The ratio of Hui nationality to Han nationality in the current ethnic structure in the block is about 1.5:1 (Huang, 2015). Among them, most of the Hui nationality has lived here for generations, and a few Hui Muslims in Gansu, Ningxia, Henan and other provinces choose to work here. The Han nationality is mostly migrant workers who live here for a long time by renting houses. The ethnic relationship in the block is gradually changing. According to interviews, migrant workers from other places show heterogeneity due to the low correlation between themselves and the local cultural memories. They mainly interact with immigrant groups, and rarely take the initiative to integrate into the collective memory space of the block, showing weak sense in "cultural identity and belonging". Indigenous people in the block have different attitudes towards immigrants from other places. Some people think that immigrants lack sense of responsibility and belonging. It is believed that immigrants do not pay attention to the protection of local culture, but become competitors of the resources of the place where they moved in. The chaos of the social structure and the increase in employment pressure make the indigenous people have a negative sense of place. As a result, the aborigines show repulsive thoughts and behaviors for foreign migrant workers. However, another part of local residents believe that migrant workers have promoted the diversity of the block tourism industry, stimulated the vitality of the block, catalyzed the population integration and national integration of the block, and made a significant contribution to the development of the tourism industry in the ingoing area; moreover, a place should be more inclusive and open to develop.

The dynamic change process of multi-ethnic relationship interaction is the main factor of the evolution of collective memory spatial structure. On the one hand, the change of ethnic relationship changes the original blood relationship and geographical relationship, and breaks the living environment and social atmosphere of the original residents. In order to prevent the invasion of modern 
foreign culture and protect local traditional culture, the aborigines in historical and cultural blocks unconsciously set up space and emotional defense lines. Due to the difficulty of integration, foreign tourist labor immigrants further aggravated the differentiation of living space, which brings a severe test to the protection of collective memory space. On the other hand, the block has shown a development trend in which the proportion of Hui nationality and Han nationality has declined significantly with age. The exchanges and interactions between the Hui nationality and Han nationality are becoming more frequent. The Beiyuanmen block is gradually transforming from closed to open.

\section{Conclusion and Discussion}

Collective memory is based on the present needs of society to construct the past, emphasizing the relationship between social groups and space. However, a series of changes during the urban transition period have caused changes in values and group relationships within historical and cultural blocks. Both functional areas and daily life areas have undergone drastic changes, leading to the reconstruction of the collective memory of historical and cultural blocks. Based on the above empirical research on the Beiyuanmen, it can be seen that in the dynamic continuation of collective memory space, the protection of iconic node spaces such as mosques always occupies an important position. In contrast, the core area of collective memory formed by the streets and lane spaces representing the life scenes of the people in the old days has gradually shifted to the edge of the block. Beiyuanmen Street has changed from a significant bridge that connected the internal social activities and external service functions of the block to an isolated island where residents rarely get involved. Residents' daily life space is constantly being squeezed and replaced. It even became a "blind spot" for the protection of historical and cultural blocks and gradually disappeared.

Comparing the spatial change process of collective memory in the historical and cultural block of Beiyuanmen, it is not difficult to find that the block has entered a state of excessive tourism development. The involvement of capital and the changes in ethnic relations have produced complex interest subjects. In addition, the relevant functional departments still lack a complete top-level design, and have not yet effectively controlled the commercial development of the Beiyuanmen block. Therefore, the non-daily consumption space continuously invades and squeezes the living space and cultural space of the aborigines. The spatial differentiation of neighborhoods continues to intensify, which in turn affects the continuation of collective memory space. Beiyuanmen block, as a residential-oriented historical and cultural block, its main value meaning is to reflect the specific life mode and neighborhood structure of the aborigines. The material space structure and social network structure formed by the aborigines based on the same cultural background, folk customs and living habits are the inner sources of the vitality of the block. However, the traditional life functions of the current block gradually fade away. The cultural foundation lacking the inheritance of the 
aboriginal people will be destroyed. It will eventually become a static piece of historical memory in the growing commercial atmosphere. The history and cultural block lacking vitality will also be reduced from a living heritage to a static heritage lacking authenticity. Then the value and significance of historical and cultural blocks will no longer exist.

In the future, historical and cultural blocks should formulate measures to protect the lifestyles of the aborigines and continue the collective memory of daily life, such as restoring part of the daily life service space in the block, especially the core area, and establishing a business control system for historical and cultural blocks. At the same time, the current historical and cultural blocks have tried different spatial construction methods to achieve the continuation of multiple collective memories. Strengthening the protection of functional compromise inheritance elements has become the basic idea of protecting the collective memory of space. But it is also necessary to pay more attention to the cultural connotation carried by the material space. Be wary of the possibility that the forgetting of incorporeal memory exceeds the forgetting of physical memory.

\section{Conflicts of Interest}

The authors declare no conflicts of interest regarding the publication of this paper.

\section{References}

Alderman, D. H., \& Inwood, J. (2013). Street Naming and the Politics of Belonging: Spatial Injustices in the Toponymic Commemoration of Martin Luther King Jr. Social \& Cultural Geography, 14, 211-233. https://doi.org/10.1080/14649365.2012.754488

Ardakani, M. K., \& Oloonabadi, S. A. (2011). Collective Memory as an Efficient Agent in Sustainable Urban Conservation. Procedia Engineering, 21, 985-988. https://doi.org/10.1016/j.proeng.2011.11.2103

Daniel, J. (2004). Memory and the Impact of Political Transformation in Public Space (pp. 1-10). Duke University Press.

David, A. (2007). Kitsch Geographies and the Everyday Spaces of Social Memory. Environment and Planning A, 39, 521-540. https://doi.org/10.1068/a3866

Guo, X., \& Quan, S. (2013). Study on Spatial Structure and Its Renewal Mode of Historical Cultural Districts of Kasha Based on Space Syntax. Architectural Journal, S2, 8-13.

Han, J., \& Wang, L. (2018). Addressing Social Network in Urban Heritage Conservation: Case Study of Muslim Quarter in Xi'an. Urban Development Studies, 25, 32-37.

Huang, J. (2010). Study on the Construction and Morphology Transition of the Drum-Tower Hui Community in Xi'an. Ph.D. Thesis, South China University of Technology.

Huang, J. (2015). The Collaborative Evolution of the Traditional Urban Hui Community and Urban Space Based on Space Syntax. Journal of Northwest University (Natural Science Edition), 219, 991-995.

Kuijk, F., Guimarães, R. L., Cesar, P., \& Bulterman, D. C. A. (2010). From Photos to Memories: A User-Centric Authoring Tool for Telling Stories with Your Photos. In: P. Daras \&, O.M. Ibarra (Eds.), User Centric Media. UCMEDIA 2009 (pp. 13-20). Springer. https://doi.org/10.1007/978-3-642-12630-7_2 
Li, Z., \& Nie, X. (2018). Mechanism of Collective Memory of Cultural Tourism Destinations on Place Attachment of Tourists: A Case of Wuzhen, Pingyao and Phoenix Town. Areal Research and Development, 37, 95-100.

Mah, A. (2010). Memory, Uncertainty and Industrial Ruination: Walker Riverside, Newcastle upon Tyne. International Journal of Urban and Regional Research, 34, 398-413. https://doi.org/10.1111/j.1468-2427.2010.00898.x

Maria, L. (2008). Place Attachment, Place Identity, and Place Memory: Restoring the Forgotten City Past. Journal of Environmental Psychology, 28, 209-231. https://doi.org/10.1016/j.jenvp.2008.02.001

Maurice, H. (2002). On Collective Memory. Shanghai People’s Publishing House.

Nagel, C. (2002). Reconstructing Space, Recreating Memory: Sectarian Politics and Urban Development in Post-War Beirut. Political geography, 21, 715-725. https://doi.org/10.1016/S0962-6298(02)00017-3

Shi, N. (1996). The Historial Atlas of Xi'an. Xi'an Cartographic Publishing House.

Steven, H., \& Alderman, D. H. (2004). Memory and Place: Geographies of a Critical Relationship. Social and Cultural Geography, 5, 347-355. https://doi.org/10.1080/1464936042000252769

Wang, F., Lu, Z., Zhang, B., Zhang, S., Dong, W., Liu, P. et al. (2017). Memory and Homesickness in Transition: Evolution Mechanism and Spatial Logic of Urban and Rural Memory. Geographical Research, 1, 3-25.

Xi'an Local Records Office (2010). Lianhu District Records. http://xadfz.xa.gov.cn/book/list.html?catid=6179d9a8-d2f5-4647-ae6c-9e26243a9626

Yang, W., Zeng, J., \& Li, Z. (2004). Protection and Development-On the Actualities and the Countermeasures for Muslim Community in China Inland City. Journal of Tianjin University (Social Sciences), 6, 70-74.

Zhou, W., \& Huang, Z. (2016). Research on the Protection and Renewal of Guangzhou Xiguan Traditional Residential Community Based on Collective Memory. Human Geography, 31, 42-49. 